\title{
Article \\ A Low Profile Dual-Band High Gain Directional Antenna for Anti-Interference WLAN Station Applications
}

\author{
Yuqing Dou, Guiting Dong, Jiafu Lin, Qibo Cai * and Gui Liu*
}

check for updates

Citation: Dou, Y.; Dong, G.; Lin, J.; Cai, Q.; Liu, G. A Low Profile Dual-Band High Gain Directional Antenna for Anti-Interference WLAN Station Applications. Appl. Sci. 2021, 11, 2007. https://doi.org/10.3390/ app11052007

Academic Editor: Ernesto Limiti

Received: 9 February 2021

Accepted: 22 February 2021

Published: 24 February 2021

Publisher's Note: MDPI stays neutral with regard to jurisdictional claims in published maps and institutional affiliations.

Copyright: (c) 2021 by the authors. Licensee MDPI, Basel, Switzerland. This article is an open access article distributed under the terms and conditions of the Creative Commons Attribution (CC BY) license (https:/ / creativecommons.org/licenses/by/ $4.0 /)$.
College of Electrical and Electronics Engineering, Wenzhou University, Wenzhou 325000, China; 184511088181@stu.wzu.edu.cn (Y.D.); 20451941039@stu.wzu.edu.cn (G.D.); jiafulin@wzu.edu.cn (J.L.)

* Correspondence: caiqibo@wzu.edu.cn (Q.C.); gliu@wzu.edu.cn (G.L.)

\begin{abstract}
This paper presents a low-profile dual-band antenna with directional radiation characteristics for wireless local area network (WLAN) applications. The proposed directional antenna is composed of a coupling microstrip line, two F-shaped strips, two rectangular strips, and a defected ground plane. The measured impedance bandwidth of the proposed antenna is $180 \mathrm{MHz}$ (2.33-2.51 GHz) and $830 \mathrm{MHz}(5.09-5.92 \mathrm{GHz})$, which can cover Institute of Electrical and Electronic Engineers (IEEE) $802.11 \mathrm{a} / \mathrm{b} / \mathrm{g}$ frequency bands. The dual-band antenna exhibits a desirable directional radiation patterns in the vertical and horizontal planes with the peak gain of $6.55 \mathrm{dBi}$ in the lower frequency band and $8.1 \mathrm{dBi}$ in the higher frequency band. The measured antenna efficiency is $70 \%$ at $2.4 \mathrm{GHz}$ and $84.5 \%$ at $5.5 \mathrm{GHz}$. The proposed dual-band WLAN station antenna is designed on a FR4 substrate with overall dimensions of $69 \mathrm{~mm} \times 50 \mathrm{~mm} \times 1.6 \mathrm{~mm}$.
\end{abstract}

Keywords: dual-band; directional radiation; microstrip line; directional antenna

\section{Introduction}

Nowadays, almost all wireless local area network (WLAN) station antennas show omnidirectional radiation patterns. However, for some applications, antennas with high gain and directional radiation characteristics are required, such as Radio Frequency Identification (RFID) reader [1], microwave imaging systems [2] and public areas with numerous WLAN antennas from different mobile operators. Although the structure of the directional antennas is complicated, it has vital practical significance due to its reduced sensitivity to environmental interference.

In order to obtain the directional radiation pattern, there are many methods used in antenna design [3,4]. In [3], a patch is used as the last-order resonator of the network and the radiating element to realize a directional patch antenna. In [4], double reflecting floors are introduced in the dipole antenna to obtain stable radiation patterns and relatively high gains in the upper frequency band. For the needs of specific systems, some antennas have the characteristics of being low profile, compact and wideband, and have stably directional radiation [5-7]. A monopole antenna with a fork-shaped slot electromagnetic bandgap (EBG) structure as a reflector is proposed in [5]. The fork-shaped EBG eliminates the adverse effect of the metal sheet on the performance of the monopole antenna. The bended structure can be used to realize a low profile and compact directional antenna. In [6], the antenna is based on a modified Vivaldi antenna and characterized by a three-dimensionally bended structure, which performs a stable directional radiation pattern on wideband and is of compact size. In [7], four bent diamond-shaped half-loops are placed on the ground plane to form a directional antenna, and half-loops are fed by a feed network to realize a cardioid directional radiation pattern.

For directional antennas, high gain performance becomes an important consideration [8-15]. The classic Yagi antenna [8,9] is a good solution for designing high-gain directional antennas, but the disadvantages are large size and narrow bandwidth. As a 
narrowband antenna, it is time-consuming to design a dual-band Wi-Fi Yagi array. QuasiYagi antennas [10-12] can increase the impedance bandwidth, but the gain performance is not as good as that of the Yagi antenna. In general, it is a challenge to design a wideband and compact Yagi antenna. Slot antennas are often used as high-gain directional antennas. A multiband antenna with directional radiation can be obtained by loading slots on the radiator. Currently, slot antennas have been widely studied as directional antennas $[13,14]$. A directional slot antenna with a squared arch structure is presented to achieve impedance matching, high gain, and vertical polarization in dual band Wi-Fi unidirectional antenna design [13]. A slot in a ground plane with a complimentary microstrip stub was exploited to design a high-gain directional antenna with high radiation efficiency [14]. Based on the characteristics of the slot antenna, a slot-loop antenna, equivalent to a dipole array, is proposed, showing high-efficiency directional characteristics [15]. The size of the slot loop antenna is smaller than that of the Yagi antenna, and it is a suitable candidate as a high gain directional antenna.

In this paper, a dual-band antenna with directional radiation patterns is presented. Two symmetrical rectangular strips and F-shaped strips are introduced into the ground layer to form good impedance matching, thereby realizing a dual-band antenna. A large ground plane and a microstrip line are combined to form a high-gain directional antenna. The size of the dual-band antenna is $50 \times 69 \times 1.6 \mathrm{~mm}^{3}$ with a gain of $6.55 \mathrm{dBi}$ and $8.1 \mathrm{dBi}$ at two resonant frequencies, respectively. The proposed dual-band antenna exhibits good directional radiation characteristics for wireless local area network (WLAN) applications.

\section{Antenna Geometry and Design}

The geometry of the proposed antenna is shown in Figure 1. The presented antenna consists of a coupling microstrip line, two F-shaped strips, two rectangular strips and a defected ground plane. The coupling microstrip line is printed on the top side of the substrate. The two F-shaped strips, two rectangular strips and the defected ground plane are printed on the bottom side of the substrate. The coupling microstrip line is fed by a coaxial SubMiniature version A (SMA) connector through the ground plane. The proposed antenna is fabricated on a $50 \mathrm{~mm} \times 69 \mathrm{~mm}$ FR4 substrate with relative permittivity $\varepsilon \mathrm{r}$ of 4.4 , loss $\tan \delta$ of 0.02 , and thickness of $1.6 \mathrm{~mm}$.

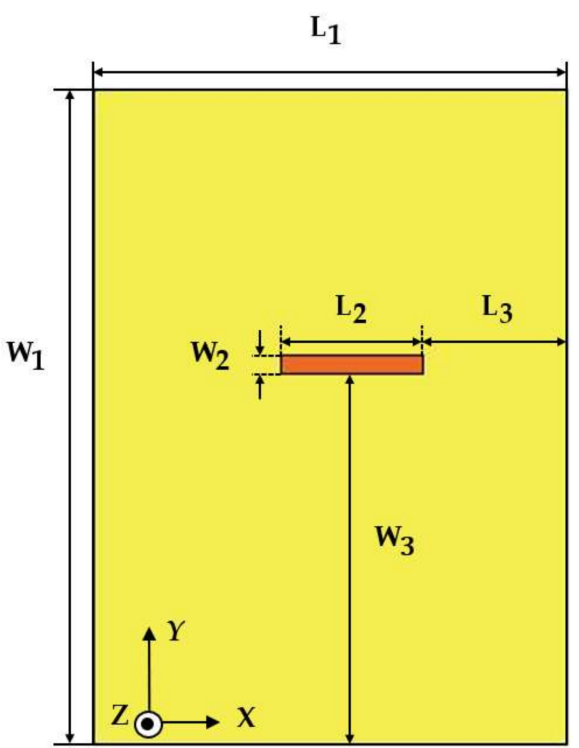

(a)

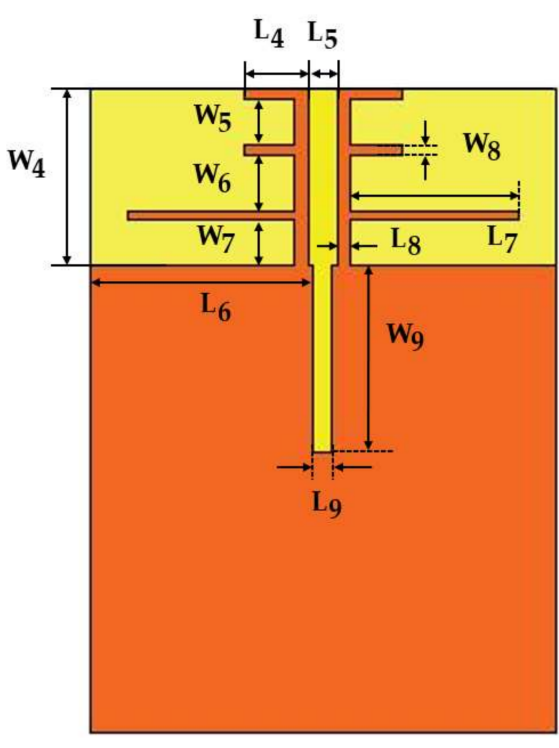

(b)

Figure 1. Geometry of the proposed antenna. (a) Top view; (b) Bottom view.

The defected ground plane is connected to two symmetrical rectangular strips and two symmetrical F-shaped strips. A rectangular slit is etched in the middle of the ground plane 
to enhance the impedance matching and realize a high gain of the directional antenna. In addition, the coupling between the rectangular microstrip line and rectangular slit results in good directional radiation characteristics. In order to achieve the dual-band characteristics of the presented antenna, two symmetrical F-shaped strips are introduced into the ground plane near the upper part of the rectangular slit. A rectangular strip with a length of $\mathrm{L}_{7}$ and a width of $W_{8}$ is added to the F-shaped structure to provide impedance matching at the desired frequency bands. The two rectangular strips and F-shaped strips are used to obtain good impedance matching in the lower and higher frequency bands, respectively.

A photograph of the manufactured antenna is shown in Figure 2.

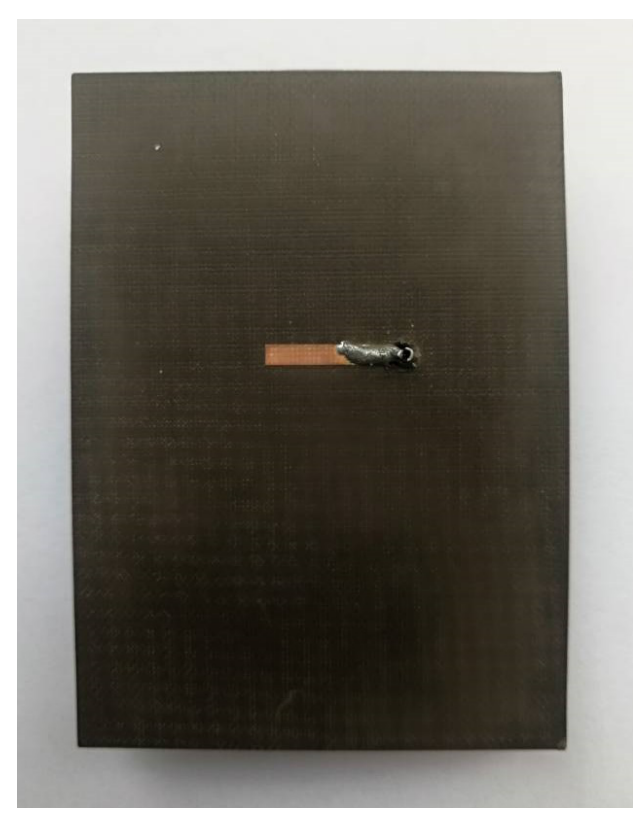

(a)

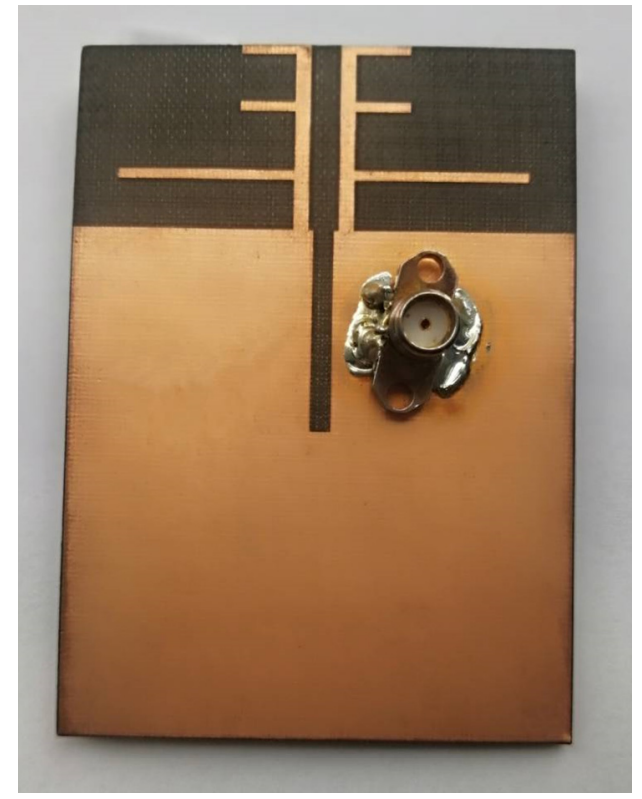

(b)

Figure 2. Photograph of the manufactured antenna. (a) Top view; (b) Bottom view.

The design and optimization of the entire antenna are completed with the 3D full-wave high frequency structural simulator (HFSS). In order to further study the influence of the ground plane on the proposed antenna, the current distribution of the antenna at different frequency bands has been investigated. The simulated current distribution at $2.4 \mathrm{GHz}$ and $5.5 \mathrm{GHz}$ is shown in Figure 3. As shown in Figure 3a, the surface currents are concentrated on the edge of the rectangular strips at $2.4 \mathrm{GHz}$. The current mainly flows along the two F-shaped strips at $5.5 \mathrm{GHz}$, as shown in Figure 3b. Therefore, we can adjust the dimension of the rectangular strips and the F-shaped strips to generate a lower and higher resonant frequency, respectively. In Figure 3, it can be seen that most of the current is concentrated around the rectangular slit. The current in the vertical direction is in the opposite direction, which can cancel part of the radiation. The current in the horizontal direction is almost in the same direction, which can enhance part of the radiation. Therefore, the characteristics of directional radiation can be realized.

According to the results of the current distribution diagram, the antenna can be optimized by adjusting the dimension of the F-shaped strips and the rectangular strips. During the optimization process, one geometric parameter is adjusted, and the other parameters remain fixed. Figure $4 a, b$ illustrate the reflection coefficients of the presented antenna with different values of $\mathrm{L}_{7}$ and $\mathrm{L}_{4}$, respectively. As shown in Figure $4 \mathrm{a}$, the value of $L_{7}$ mainly affects the lower frequency band. It can be seen that when $L_{7}$ is $18 \mathrm{~mm}$, the proposed antenna operates at the desired lower frequency band. Figure $4 \mathrm{~b}$ shows the effect of different values of $\mathrm{L}_{4}$ on the higher frequency band. When $\mathrm{L}_{4}$ is $6.5 \mathrm{~mm}$, the desired 
higher frequency band is obtained. The final parameters of the proposed antenna are listed in Table 1.
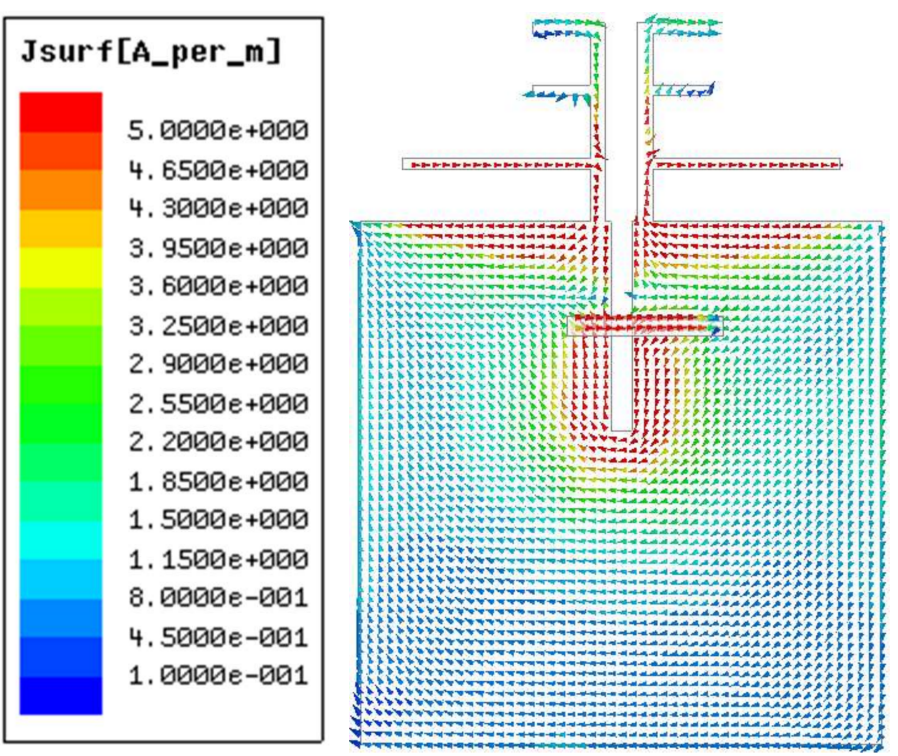

(a)

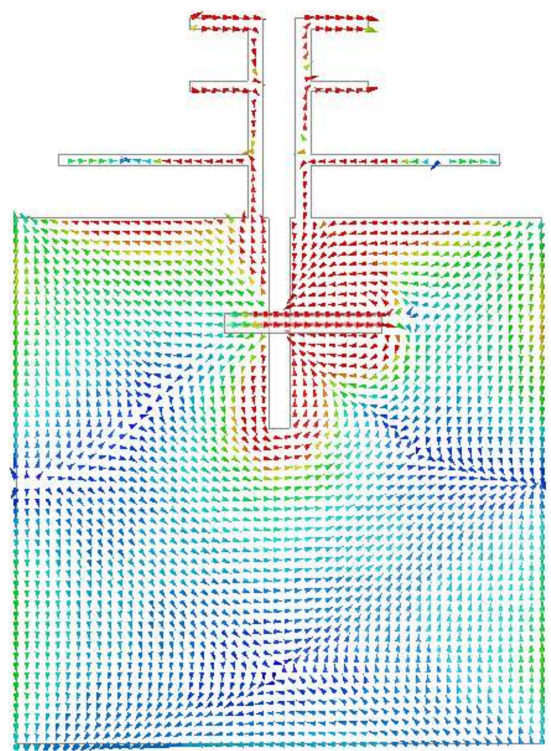

(b)

Figure 3. Surface current distributions at (a) $2.4 \mathrm{GHz}$; (b) $5.5 \mathrm{GHz}$.

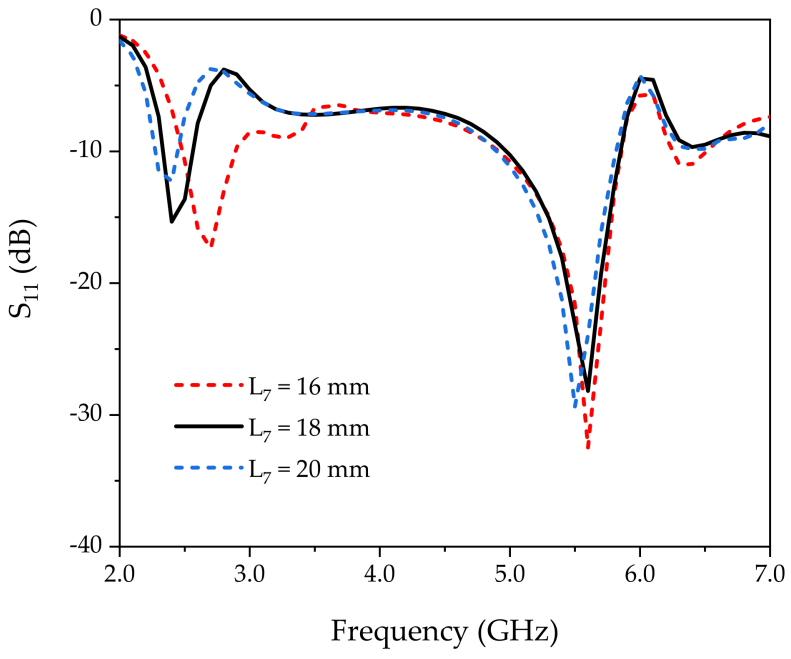

(a)

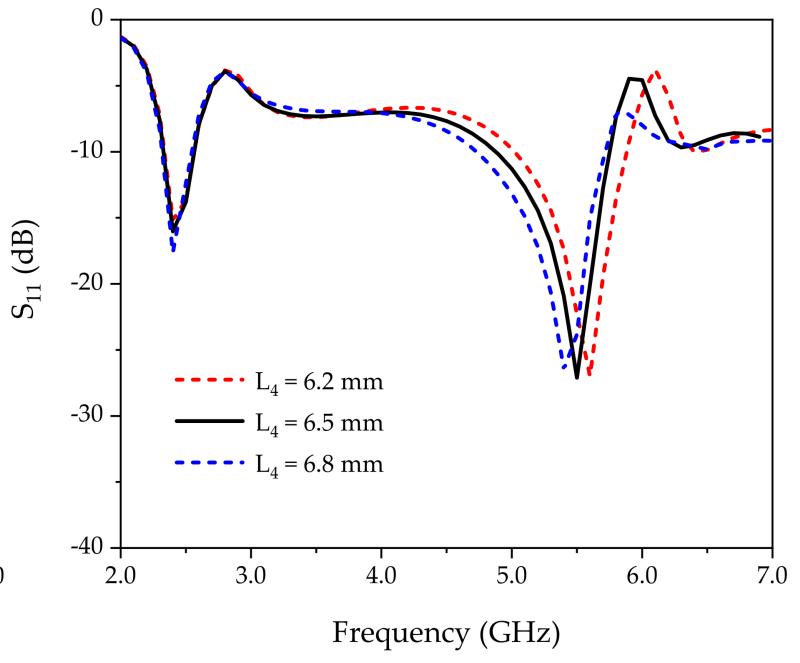

(b)

Figure 4. Simulated reflection coefficient for different values of (a) $\mathrm{L}_{7}$ and (b) $\mathrm{L}_{4}$.

Table 1. Parameters of the proposed antenna (unit: $\mathrm{mm}$ ).

\begin{tabular}{cccccc}
\hline Parameters & Value & Parameters & Value & Parameters & Value \\
\hline $\mathrm{W}_{1}$ & 69 & $\mathrm{~W}_{7}$ & 5 & $\mathrm{~L}_{4}$ & 6.5 \\
$\mathrm{~W}_{2}$ & 2 & $\mathrm{~W}_{8}$ & 1 & $\mathrm{~L}_{5}$ & 3 \\
$\mathrm{~W}_{3}$ & 39 & $\mathrm{~W}_{9}$ & 20 & $\mathrm{~L}_{6}$ & 24 \\
$\mathrm{~W}_{4}$ & 19 & $\mathrm{~L}_{1}$ & 50 & $\mathrm{~L}_{7}$ & 18 \\
$\mathrm{~W}_{5}$ & 5 & $\mathrm{~L}_{2}$ & 15 & $\mathrm{~L}_{8}$ & 1.5 \\
$\mathrm{~W}_{6}$ & 6 & $\mathrm{~L}_{3}$ & 15.3 & $\mathrm{~L}_{9}$ & 2 \\
\hline
\end{tabular}




\section{Results and Discussion}

Figure 5 shows the simulated and measured reflection coefficients $\left(S_{11}\right)$ of the proposed antenna. It can be seen that the measured $S_{11}$ are in good agreement with simulation. From the measurement results, we can see that the bandwidth of $-10 \mathrm{~dB}$ reflection coefficient is $180 \mathrm{MHz}(2.33-2.51 \mathrm{GHz})$ at the lower frequency band and $830 \mathrm{MHz}(5.09-5.92 \mathrm{GHz})$ at the higher frequency band. Therefore, the two operating frequency bands can cover IEEE $802.11 \mathrm{a} / \mathrm{b} / \mathrm{g}$ (WLAN, 2.4-2.4835 GHz, 5.15-5.35 GHz, 5.725-5.85 GHz) frequency bands.

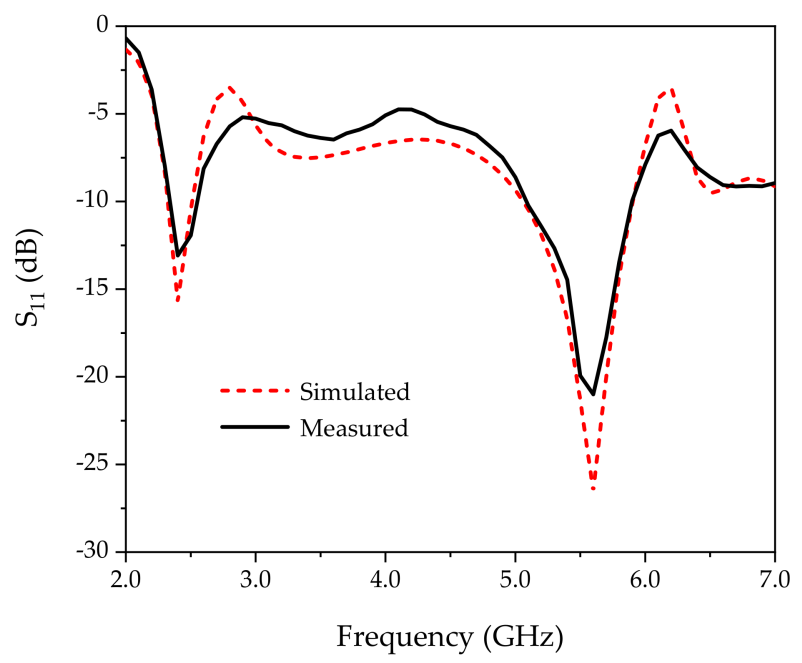

Figure 5. Simulated and measured $S_{11}$ of the proposed antenna.

Figure 6 shows the normalized measured radiation patterns of the proposed antenna at $2.4 \mathrm{GHz}$ and $5.5 \mathrm{GHz}$. The solid and dash lines represent co-polarization and cross-polarization, respectively. The proposed antenna exhibits unidirectional radiation performance, and no obvious sidelobe and split the beam in the main radiation direction at the desired two frequencies. The cross-polarization for both the E-plane (xoz plane) and the $\mathrm{H}$-plane (yoz plane) are less than $-20 \mathrm{~dB}$. The antenna exhibits lower cross-polarization levels at the lower and the higher frequency bands. It can be seen from Figure 6 that the beamwidth of the E-plane is narrower than that of H-plane. The beamwidth of the E-plane is about $60^{\circ}$, while the beamwidth of the H-plane is about $120^{\circ}$. The narrower beamwidth in the E-plane can facilitate the separation of desired signals from interference. The results in Figure 6 indicate that the radiation patterns demonstrate the desired directional performance at $2.4 \mathrm{GHz}$ and $5.5 \mathrm{GHz}$.

The measured gain and total efficiency are shown in Figure 7. The measured gain is $6.55 \mathrm{dBi}$ at $2.4 \mathrm{GHz}$ and $8.1 \mathrm{dBi}$ at $5.5 \mathrm{GHz}$. The measured antenna efficiency is $70 \%$ and $84.5 \%$ at the lower and the higher frequency band, respectively. The measured gain and efficiency of the proposed directional antenna demonstrate an upward trend, with larger values at the higher frequency bands. 


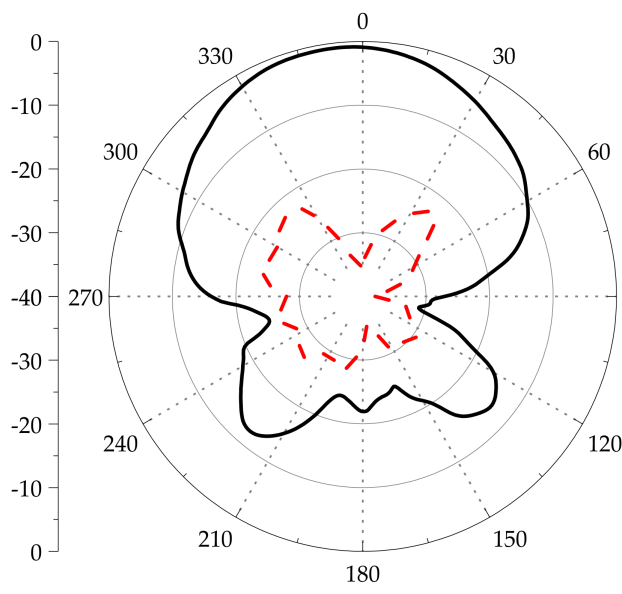

(a)

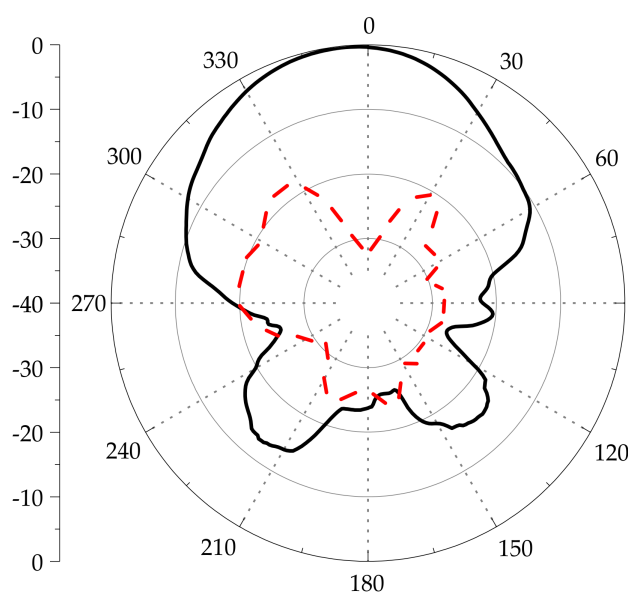

(c)

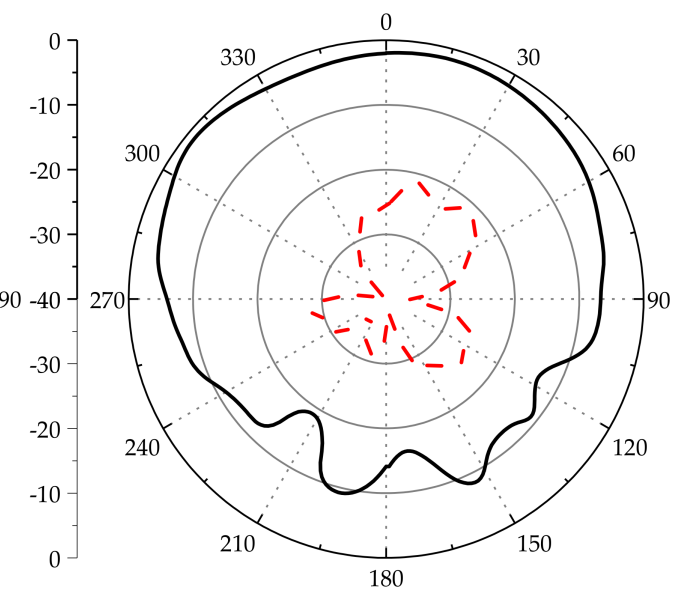

(b)

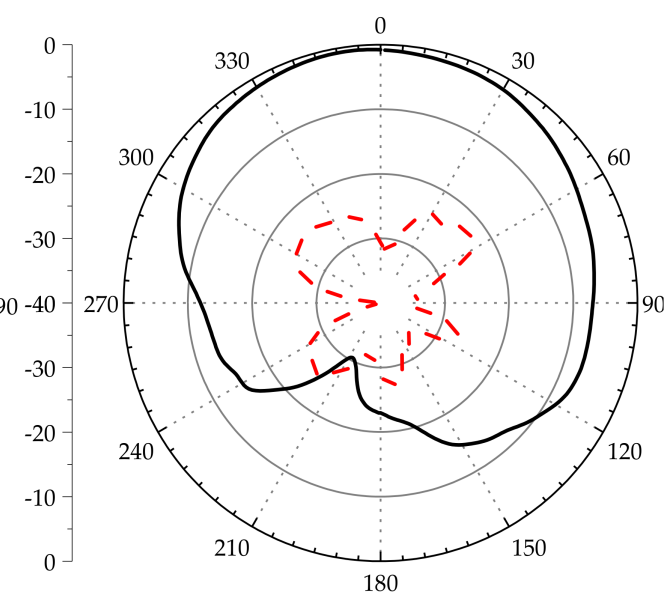

(d)

Figure 6. Radiation patterns of the proposed antenna: (a) $2.4 \mathrm{GHz}$ E-plane, (b) $2.4 \mathrm{GHz}$ H-plane, (c) $5.5 \mathrm{GHz}$ E-plane, and (d) $5.5 \mathrm{GHz}$ H-plane.

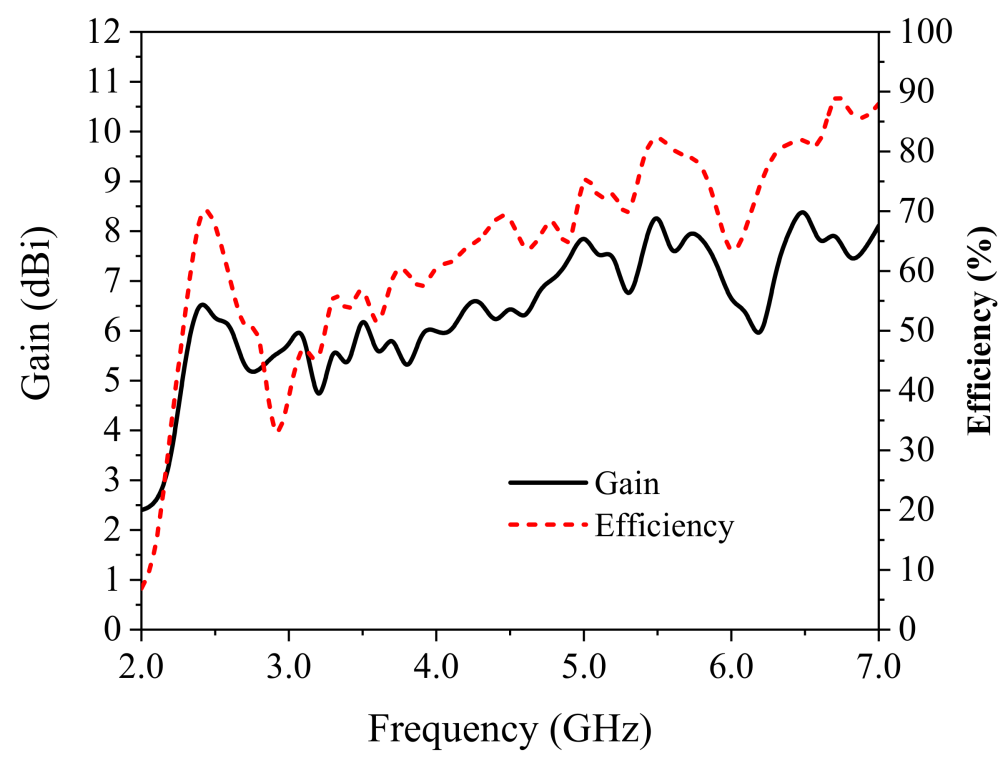

Figure 7. Measured gain and efficiency. 


\section{Conclusions}

In this paper, a dual-band directional antenna has been designed and fabricated. Two symmetrical rectangular strips and two symmetrical F-shaped strips are introduced to obtain the lower and higher frequency bands, respectively. The printed antenna is excited by a coupling rectangular microstrip. Simulated and measured $S_{11}$ agree very well at the desired frequency bands. The directional antenna exhibits a stable directional radiation pattern with measured gain of $6.55 \mathrm{dBi}$ at the lower frequency bands and $8.1 \mathrm{dBi}$ at the higher frequency bands. The proposed dual-band directional antenna is a promising candidate for WLAN stations with characteristics of anti-interference, high radiation efficiency and high gain.

Author Contributions: Conceptualization, Y.D.; methodology, J.L. and G.L.; investigation, G.D.; writing—original draft preparation Y.D.; writing—review and editing Q.C. and G.L.; supervision and funding acquisition, G.L. All authors have read and agreed to the published version of the manuscript.

Funding: This research work was partially funded by National Natural Science Foundation of China under Grant No. 61671330and No. 61340049 the Science and Technology Department of Zhejiang Province under Grant No. LGG19F010009, and Wenzhou Municipal Science and Technology Program under Grant No. C20170005 and No.2018ZG019.

Data Availability Statement: The data supporting this research article are available upon request to the corresponding author.

Conflicts of Interest: The authors declare that there is no conflict of interest regarding the publication of this manuscript.

\section{References}

1. Zeng, Y.; Chen, Z.N.; Qing, X.; Jin, J. A Directional, Closely Spaced Zero-Phase-Shift-Line Loop Array for UHF Near-Field RFID Reader Antennas. IEEE Trans. Antennas Propag. 2018, 66, 5639-5642. [CrossRef]

2. Mobashsher, A.T.; Abbosh, A.M. Performance of Directional and Omnidirectional Antennas in Wideband Head Imaging. IEEE Antennas Wirel. Propag. Lett. 2016, 15, 1618-1621. [CrossRef]

3. Mao, C.; Gao, S.; Wang, Y.; Sanz-Izquierdo, B. A Novel Multiband Directional Antenna for Wireless Communications. IEEE Antennas Wirel. Propag. Lett. 2017, 16, 1217-1220. [CrossRef]

4. Zhang, H.; Jiao, Y.; Weng, Z. A Novel Dual-Wideband Directional Dipole Antenna with Double Reflecting Floors. IEEE Antennas Wirel. Propag. Lett. 2017, 16, 1941-1944. [CrossRef]

5. Sambandam, P. Compact Monopole Antenna Backed with Fork-Slotted EBG for Wearable Applications. IEEE Antennas Wirel. Propag. Lett. 2020, 2, 228-232. [CrossRef]

6. Liu, J. A Low-Profile, Directional, Ultrawideband Antenna. IEEE Antennas Wirel. Propag. Lett. 2019, 18, 255-259. [CrossRef]

7. Ghaemi, K.; Behdad, N. A Low-Profile, Wideband Antenna with Vertically Polarized Directional Radiation. IEEE Antennas Wirel. Propag. Lett. 2016, 15, 1093-1096. [CrossRef]

8. Fezai, F.; Menudier, C.; Thevenot, M.; Monediere, T. Systematic Design of Parasitic Element Antennas-Application to a WLAN Yagi Design. IEEE Antennas Wirel. Propag. Lett. 2013, 12, 413-416. [CrossRef]

9. Li, Y.; Sun, S.; Yang, F. A Miniaturized Yagi-Uda-Oriented Double-Ring Antenna with Circular Polarization and Directional Pattern. IEEE Antennas Wirel. Propag. Lett. 2013, 12, 945-948. [CrossRef]

10. Yeo, J.; Lee, J. Bandwidth Enhancement of Double-Dipole Quasi-Yagi Antenna Using Stepped Slotline Structure. IEEE Antennas Wirel. Propag. Lett. 2016, 15, 694-697. [CrossRef]

11. Wu, J.; Zhao, Z.; Nie, Z.; Liu, Q. Bandwidth Enhancement of a Planar Printed Quasi-Yagi Antenna with Size Reduction. IEEE Trans. Antennas Propag. 2014, 62, 463-467. [CrossRef]

12. Ding, Y.; Jiao, Y.C.; Fei, P.; Li, B.; Zhang, Q.T. Design of a Multiband Quasi-Yagi-Type Antenna with CPW-to-CPS Transition. IEEE Antennas Wirel. Propag. Lett. 2001, 10, 1120-1123. [CrossRef]

13. Xiao, Y.; Qi, Y.; Li, F.; Fan, J.; Yu, W.; Lu, L. Dual-Band Directional Slot Antenna for Wi-Fi Application. IEEE Trans. Antennas Propag. 2018, 66, 4277-4281. [CrossRef]

14. Rooyen, M.V.; Odendaal, J.W.; Joubert, J. High-Gain Directional Antenna for WLAN and WiMAX Applications. IEEE Antennas Wirel. Propag. Lett. 2017, 16, 286-289. [CrossRef]

15. Chi, L.; Qi, Y.; Weng, Z.; Yu, W.; Zhuang, W. A Compact Wideband Slot-Loop Directional Antenna for Marine Communication Applications. IEEE Trans. Veh. Technol. 2019, 68, 2401-2412. [CrossRef] 